\title{
Dry mixes for the restoration: basic principles of design
}

\author{
Nina Shangina ${ }^{1}$, Yuriy Pukharenko ${ }^{2}$, Alexey Kharitonov ${ }^{2 *}$ and Tatiana Kharitonova $^{2}$ \\ ${ }^{1}$ Petersburg State Transport University, Moskovsky pr. 9, 190031 Saint Petersburg, Russia \\ ${ }^{2}$ Saint-Petersburg State University of Architecture and Civil Engineering, 2-nd Krasnoarmeiskaya St. \\ 4, 190005 Saint Petersburg, Russia
}

\begin{abstract}
To ensure compliance with historic solutions as the primary binder of dry mixes for the restoration is air lime. To date, almost all of the advantages and disadvantages of the lime-based mortars are known, and this allows implementing a scientific approach to the goal of ensuring the maximum possible durability of masonries and finishing designs. This article covers the main problems and goals faced by professionals in the field of producing dry building mixtures that are the most technologically and economically appropriate for the restoration of the historical buildings and constructions. The use of modern mineral additives opens up new prospects for improving the properties of lime dry mixtures, for both new construction and restoration works of the objects of historical heritage.
\end{abstract}

\section{Introduction}

Authentic recreation of the original appearance of buildings and constructions largely depends on the correct choice of building materials; they have to ensure the connection with the architectural and historical environment and have to be in compliance with the constructional features of the restored objects. However, restoration works in the third millennium have to be based on the modern developments in the field of building materials, if they do not contradict the common goals of the restoration. Dry building mixtures do meet the above mentioned requirements; they are produced with the use of the latest scientific developments that allow improving technical properties of traditional materials, while retaining their historic identity.

Some of the most important materials, used for the construction of the buildings, currently considered architectural monuments, were mortars based on air binders, such as lime. This determines a fundamental choice of air hardening lime as a main binder for the dry restoration mixtures, it is still widely used for construction works in spite of the development of new types of binders.

The main goal for the builders has always been increasing durability of building materials and also overcoming the main disadvantages of lime - low strength and lack of water resistance. Thus, in ancient China, rice paste and tung oil were used for this purpose.

\footnotetext{
*Corresponding author: peepdv@mail.ru
} 
Russian chronicles indicate that decoction of spruce bark, cottage cheese, egg whites, cow's milk, linseed oil or ox blood were added to the mortars.

From the modern point of view the use of such additives is unacceptable for economic and technological reasons.

\section{The principles of compatibility of the restoration blends with the substrate}

A significant increase in the strength characteristics of the building mixtures was possible with the development of hydraulic binders that do not have the same deficiencies as lime. At the same time, the main advantage of cement - its high strength is not an essential property for finishing mortars. Strength is not the main indicator even for masonry mortars. Thus, by increasing the strength of the solution by 2 times, the strength of the masonry increased only by $10-12 \%$, i.e. reducing material efficiency [1].

\subsection{The vapor permeability}

A more significant characteristic of finishing materials is their vapor permeability, which determines the amount of condensed moisture in the load-bearing structures and, therefore, affects the heat engineering performance and durability. Lime-based mortars significantly exceed cement-based mortars by vapor permeability (Table. 1).

Table 1. Vapor permeability of mortars [2].

\begin{tabular}{|c|c|}
\hline $\begin{array}{c}\text { Type of a mortar } \\
\text { (binder:sand) }\end{array}$ & $\begin{array}{c}\text { Coefficient of vapor permeability } \\
\text { in } \mathrm{kg} / \mathrm{m} \text { hour mm water column }\end{array}$ \\
\hline $\begin{array}{c}\text { Lime-based mortar } \\
1: 1\end{array}$ & $0,07 \cdot 10^{-3}$ \\
$1: 2$ & $0,37 \cdot 10^{-3}$ \\
$1: 3$ & $0,594 \cdot 10^{-3}$ \\
\hline Cement-based mortar: & $0,00322 \cdot 10^{-3}$ \\
$1: 3$ & $0,0957 \cdot 10^{-3}$ \\
$1: 6$ & $0,742 \cdot 10^{-3}$ \\
\hline Type of a mortar & Coefficient of vapor permeability \\
(binder:sand) & in $\mathrm{kg} / \mathrm{m}$ hour mm water column \\
\hline
\end{tabular}

It must be admitted that so far there is no clear explanation of the differences that exist in the mechanism of moisture sorption for lime-based and cement-based mortars. One can only assume that since, in accordance with the theory of monomolecular adsorption [3], adsorption "is caused by the forces of residual chemical valence", the reason of the greater permeability of lime mortars is in difference in size and pore structures, and the number of free active sites on the pore surface.

Replacement of lime-based mortars for cement-based mortars during restoration works can disrupt the processes of migration of moisture through the building envelop and cause negative effects in the form of frost destruction, detachment of finishing coats and so on.

In addition, the high vapor permeability of lime-based mortars improves the indoor climate of the premises, where they were used, and that should be taken into account for new construction. Lime-based mortars regulate humidity inside buildings - they are easily absorbing excess moisture and as easily give it back if the relative degree of humidity in the room drops. 


\subsection{The crack resistance}

Quality of finishing works is also largely determined by the absence of any cracks. There are a lot of different reasons that can cause cracks, but the main ones are shrinking under the influence of physical and chemical processes while hardening, humid and carbonation shrinkage, as well as non-uniform thermal expansion of structures of heterogeneous materials.

It is known that cracks appear under the influence of internal and external factors that cause tension deformations exceeding the maximum extensibility of the material. Indirectly, the crack resistance of the materials can be judged from the relation of compressive strength/flexural strength (the higher the ratio, the higher the crack resistance), as well as the time of occurrence of cracks in a sample ring (R. L'Hermite method). Fig. 1 and Fig. 2 graphically present data evidence of a higher fracture toughness of lime-based mortars compared with cement-based mortars. The graphs are based both on literature sources [4] and our own research.

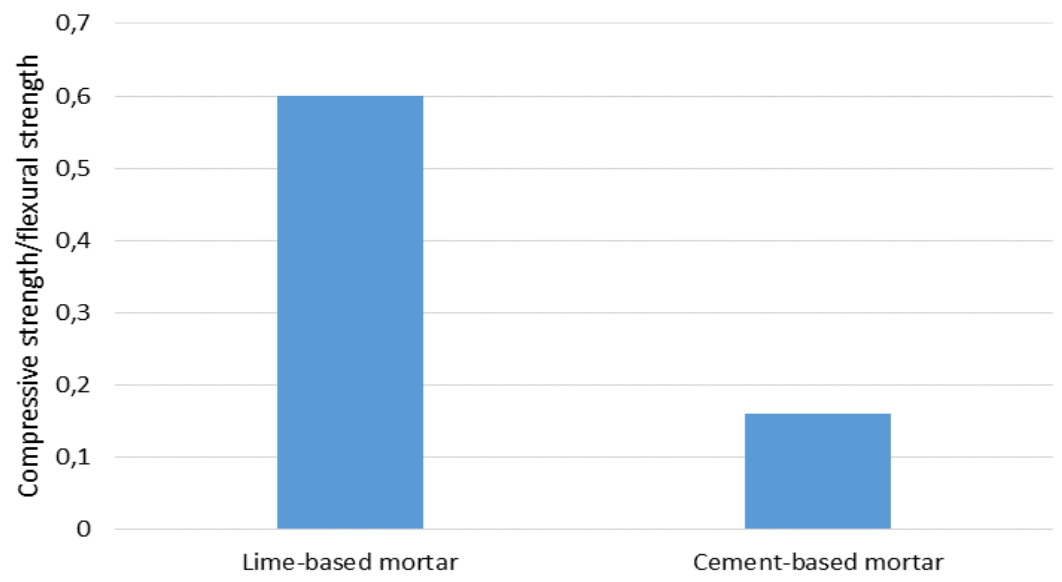

Fig. 1. Compressive strength/flexural strength ratio for lime-based and cement-based mortars.

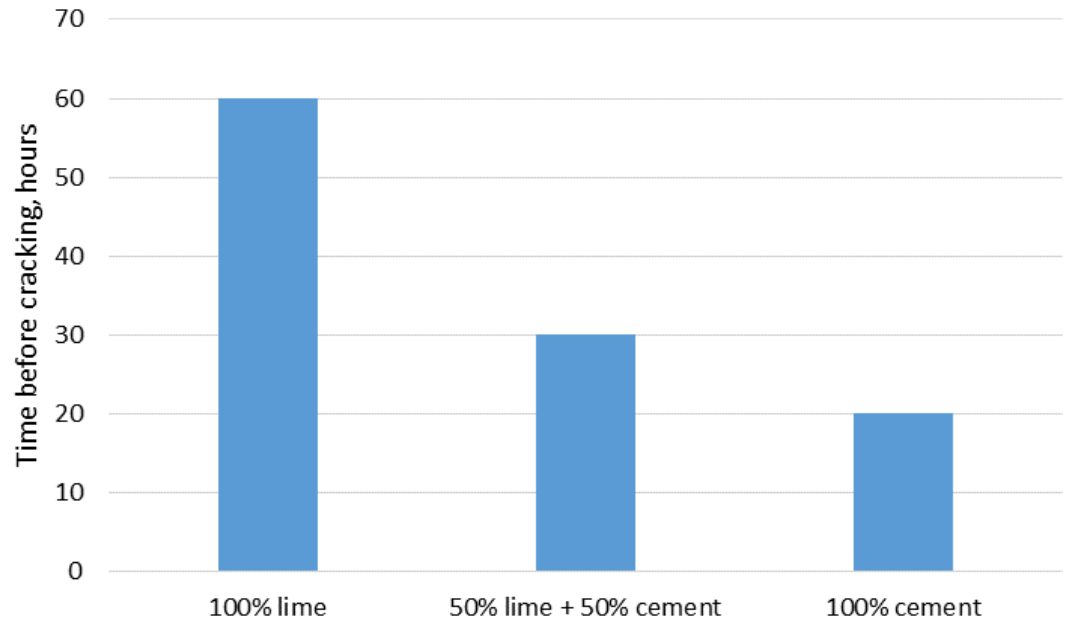

Fig. 2. Time before cracking. 
Another assessment of crack resistance of plaster coating is a measure of fracture toughness $\mathrm{KR}$, which is directly proportional to the tensile strength and inversely proportional to the modulus of elasticity in tension and shrinkage during curing. Maximum high value of this coefficient shows a low tendency to form shrinkage cracks. Estimated values of this parameter according to [5] are shown in Table. 2.

Table 2. Indicators of crack resistance and deformability of mortars.

\begin{tabular}{|l|c|c|c|}
\hline $\begin{array}{c}\text { Type of a } \\
\text { mortar }\end{array}$ & $\begin{array}{c}\text { Coefficient of crack } \\
\text { resistance, } \mathrm{K}_{\mathrm{R}}\end{array}$ & $\begin{array}{c}\text { Shrinkage } \\
\mathrm{mm} / \mathrm{m}\end{array}$ & $\begin{array}{c}\text { Intumescence, } \\
\mathrm{mm} / \mathrm{m}\end{array}$ \\
\hline Lime & 0,02 & 0,8 & 0,4 \\
\hline Lime-cement & 0,04 & 0,8 & 0,3 \\
\hline Cement & 0,10 & 0,7 & 0,2 \\
\hline
\end{tabular}

According to the Table 2, it can be said that the increase in strength and, accordingly, in the water resistance of the mortar due to addition of cement, also increases the resistance to cracking and shrinkage because of humidity.

It is important to note a considerable incipient shrinkage of lime-based mortars while drying. This happens due to the high water demand of lime mixtures, as shrinkage is directly proportional to the moisture content of the compositions.

The other important fact is that the crack resistance is connected to the adhesion of a plaster layer to a brick base. The strength of the adhesion to the base is proportional to the flexural strength and lime-based mortars have an obvious advantage in this respect. If the technology regulations are met, lime-based mortars have good adhesion to the base, which also protects the plaster from cracking. And, finally, it is known that as a result of carbonation, lime mixtures can compensate shrinkage. This property explains the effect of "self-healing" of cracks in lime-based mortars observed in some cases.

Thus, the search for the ways to increase the fracture toughness of finishing compositions must link two oppositely directed aims: increasing the strength to create a rigid matrix, which prevents deformation, shrinkage from the humidity; as well as preservation of the deformability of the mortar, sufficient for stress relaxation. These aims should be fully considered while modifying lime-based mortars with mineral and chemical additives.

\subsection{Other features lime-based mortars}

An important benefit of lime-based mortars is their resistance to biodeterioration. The mortars, derived from dry mixtures based on lime, are resistant to biological corrosion, which is caused by high $\mathrm{pH}$ (alkaline), usage of sand that underwent the heat treatment and removal of silt particles, and also from the lack of organic additives in the mortars.

Another significant factor, both for the restoration and new construction, is the possibility of carrying out finishing works at low positive or moderately low temperatures.

It is well known that while using Portland cement-based mortars in the similar conditions, it is necessary to add antifreeze agents to their structure and/or curing accelerators. However, buildings, built or decorated with the use of such mortars, have a constant problem in the future - the formation of salt efflorescence. This problem is aggravated by the use of ceramic bricks, as their raw mix contains a large amount of $\mathrm{K}, \mathrm{Na}$, $\mathrm{Mg}, \mathrm{Ca}$ and $\mathrm{SO}_{4}$. 
Hardening of a lime-based mortar happens due to evaporation of moisture and carbonation. A unique feature of lime is the increase of its solubility with decreasing temperature. Thus, at $\mathrm{t}=20^{\circ} \mathrm{C}$ the solubility is 0.166 gram per 100 grams of water, and at $\mathrm{t}$ $=0{ }^{\circ} \mathrm{C}-0.173 \mathrm{~g}$. This property can be effectively used in the development of dry mixtures intended for use at low temperatures $\left(-5^{\circ} \mathrm{C}\right)$ without antifreeze additives. Fig. 3 presents the empirical data that shows that the hardening of the mortar at a temperature of $-5{ }^{\circ} \mathrm{C}$ is accompanied by even a slight increase in strength.

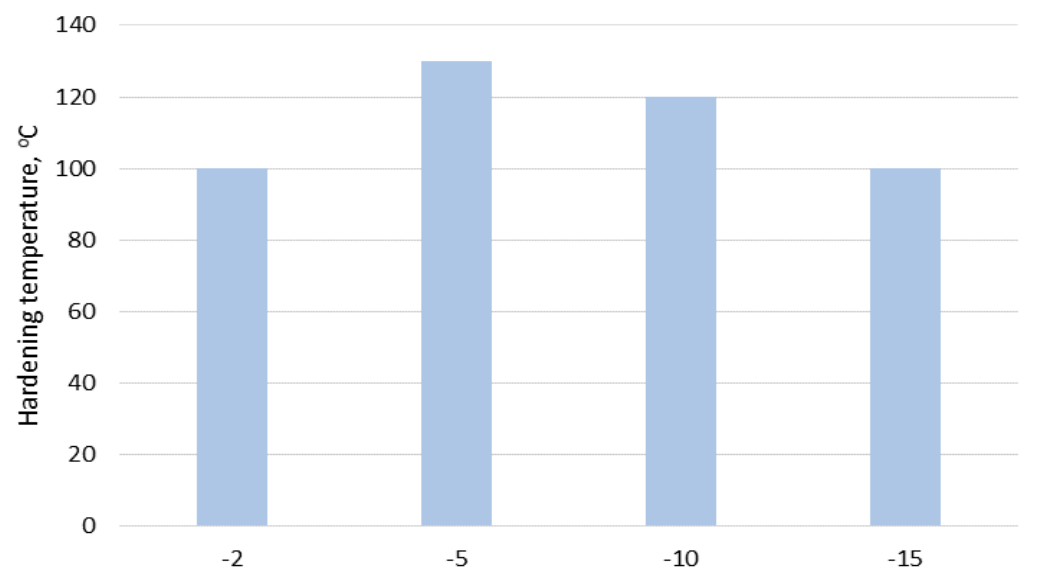

Fig. 3. Compressive strength of a mortar depending on the hardening temperature

Thus, analyzing the advantages and disadvantages of lime-based mortars, you can make a firm conclusion that they should be used not only in accordance with the methods traditional in restoration of architectural heritage, but also for new constructions.

However, insufficient water resistance and strength, as well as shrinkage by evaporation of water during the first phase of hardening, require further research to improve the properties of lime-based dry mixtures.

\section{Design principles the composition of the mixture}

When designing a composition of lime-based dry building mixtures, it is necessary to solve one important task - to prepare a mortar with appropriate physical and mechanical properties, regardless of fluctuations in temperature and humidity.

There is a known method, when ground quick lime is added to slaked lime. The heat, released during the slaking of lime, accelerates the processes of hardening of lime-based mortars - formation of crystals of calcium hydroxide. The strength of such mortars is much higher than of those, produced on hydrated lime, and shrinking deformation occurs to a lesser extent.

Rapid evaporation and absorption of moisture by the masonry harms the process of carbonization and, therefore, the ultimate strength and crack resistance of lime-based mortars exposed to $\mathrm{CO}_{2}$.

Lime has a high water demand, and an experienced plasterer has the ability to change the content of lime in a mortar, while preparing it on-site, depending on the application conditions. The composition of dry building mixtures is stable and cannot vary depending on the weather, and the use of quick lime as an additive is also not acceptable.

Based on the above, the use of modifying agents in the dry lime-based mixtures is an essential condition. The most common type of additives in dry building mixtures is water- 
retaining agents. In our opinion, the use of such additives in dry lime-based mixtures is not practical. First of all, lime has already a high water demand, and secondly, in case of humid weather lime mixtures with the additives will harden very slowly.

Therefore, while producing lime-based dry mixtures, we should focus on active mineral additives. The main criterion for selection of mineral additives for lime mixtures, in our opinion, should be not only the hydraulic activity of additives, but also its ability to influence the development of the early strength and reduced shrinkage deformation due to water retention.

There are two types of additives, which are widely used to improve the quality of limebased mortars: burnt clay and charcoal.

As an analogue of burnt clay, we use the additive, obtained by the heat treatment of kaolin at $\mathrm{t}=650-700{ }^{\circ} \mathrm{C}$. During the heat treatment, hydrogen oxides are being removed from the crystal lattice and the crystalline structure converts to amorphous metakaolin, with a large number of voids in the particle structure. The chemical composition of this additive is: $43-47 \% \mathrm{Al}_{2} \mathrm{O}_{3} ; 50-54 \% \mathrm{SiO}_{2}$ и $0,5 \% \mathrm{Fe}_{2} \mathrm{O}_{3}$. The porous structure of the amorphous metakaolin and its surface is a valuable property for the lime-based mortars [6].

Reactions involving insolubles are generally topochemical. The most important role here is played by the surface properties of a matter. Differences in the state and reactivity capacity of a solid matter throughout and on the surface of it are clearly formulated by В.Б. Алесковским (V. B. Aleskovsky) [7], solid body is considered to consist of the core and the surface functional groups.

Fig. 4 presents the distribution of adsorption sites on the surface of certain materials. Centers with different measure of the acidity $(\mathrm{pKa})$ are able to implement solid state reactions of the acid or basic type. According to the proton theory of acids and bases, an acid is a substance capable of donating a proton, and a base is a substance capable of accepting a proton.

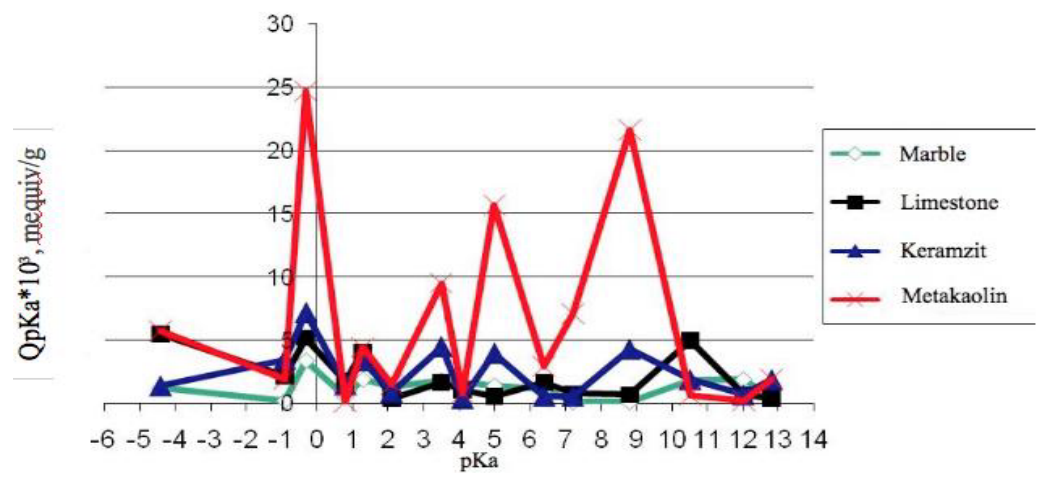

Fig. 4. Distribution of adsorption centers on the surface of some minerals

Metakaolin has a developed surface with special properties, which is characterized by a high content of Lewis acceptor centers. The ability of this type of an active center to donate a proton and hydroxylate the surface is a valuable property - developed surface of the additive retains water due to topochemical reaction. The result of the use of amorphous metakaolin in a freshly-mixed mortar is water retention and reduced shrinkage deformation. At a later stage, mineral additive increases strength and water resistance of the stone, tying lime to a hydrated newgrowths of low solubility. Effect of reducing shrinkage deformation is more noticeable in compositions with high water-binder ratio (in some cases, shrinkage is reduced from 0.8 to $0.2 \mathrm{~mm} / \mathrm{m}$ ). Thus, in the process of plastering in heated buildings (dry walls), or in low humidity environment, water content of the mortar may be increased, but this will not increase the fracturing. By examining the historical compositions, made with 
the addition of charcoal, we made the assumption that the additive not only retained water, but could also increase the rate of carbonation of lime. This hypothesis was analyzed, and it proved the effectiveness of a new type of an additive to the mortar - a nanostructured carbon. It is established that some mineral coals can be used as the additive. Coal is an organic-mineral compound that also has the gaseous phase. In coal, as well as in polymers, supramolecular structure forms a nanostructure of varying complexity. The surface of the carbon material contains oxygen-containing groups and adsorbed molecular oxygen $[8,9]$. The developed surface structure increases the role of topochemical reactions. Currently, we are carrying out studies on the use of this type of additives and establishing the thorough mechanism of their action. According to the preliminary results, it can be concluded that while using nanostructured carbon, an increase in strength is higher than while using kaolin. Thus, when using the additive in the amount of $2 \%$, the compressive strength at the age of 7 days is $50 \%$ higher than the one of the reference lime-based composition; in 28 days the gain is about $30 \%$. Also, water demand of the mixture is reduced, increasing the hydrophobicity of the mortar, and the average density decreases.

Thus, the use of modern mineral additives opens up new prospects for improving the properties of lime dry mixtures, for both new construction and restoration works of the objects of historical heritage.

\section{Acknowledges}

This study was performed in the framework of state task of Russian Federation in the sphere of scientific activity.

\section{References}

1. Y.A. Belentsov, Stroitelnye materialy Publ, 4, 60-61(2008)

2. L.B. Tsimermanis, Termodinamika vlazhnostnogo sostoianiia i tverdeniia stroitelnykh materialov [Thermodynamics of humidity conditions and hardening of building materials] (Zinatne Publ., Riga, 1985)

3. R.E. Brilling, Vozdukhopronitsaemost ograzhdaiushchikh konstruktsii i materialov [The air permeability of the enclosing structures and materials] (Stroiizdat, Moscow 1948)

4. M. Venu, Tsementy $i$ betony $v$ stroitelstve [Cement and concrete in construction] (Stroiizdat, Moscow, 1980)

5. H. Ross, F. Stahl, Shtukaturka. Prakticheskoe rukovodstvo. Materialy, tekhnika proizvodstva rabot, predotvrashchenie defektov [Plaster. A Practical Guide. Materials, equipment, prevention of defects] ( RIA Kvinte, SPb, 2006)

6. E. Aggelakopoulou, A. Bakolas, A. Moropoulou, Applied Clay Science, 53(1) 15-19 (2011)

7. Aktualnye problemy khimii tverdykh veshchestv [Actual problems of solid chemistry] edited by Aleskovskii V.B., Korsakov V.G., (Petersburg Ins. of Technology, SPb, 1992)

8. K.E. Kovalev, PhD Thesis, ( Rostov-on-Don, 2000)

9. M.N. Dubinin, Poristaia struktura i adsorbtsionnye svoistva aktivirovannykh uglei [The porous structure and adsorption properties of activated carbons] (Voennaia akad. khim. zashchity, Moscow, 1965) 